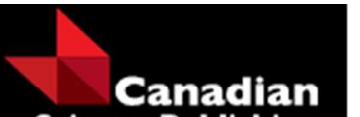

Science Publishing

Canadian Journal of Forest Research

Revue canadienne de recherche forestière

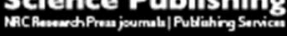

\title{
Phenolic compounds in Scots pine heartwood: are kelo trees a unique woody substrate?
}

\begin{tabular}{|r|l|}
\hline Journal: & Canadian Journal of Forest Research \\
\hline Manuscript ID & cjfr-2014-0498.R2 \\
\hline Manuscript Type: & Article \\
\hline Date Submitted by the Author: & $22-$ Sep-2015 \\
\hline Complete List of Authors: & $\begin{array}{l}\text { Venugopal, Parvathy; University of Eastern Finland, School of Forest } \\
\text { Sciences } \\
\text { Julkunen-Tiitto, Riitta; University of Eastern Finland, Natural Product } \\
\text { Research Laboratory, Department of Biology } \\
\text { Junninen, Kaisa; Metsähallitus Parks and Wildlife Finland, } \\
\text { Kouki, Jari; University of Eastern Finland, School of Forest Sciences }\end{array}$ \\
\hline Keyword: & $\begin{array}{l}\text { chemical diversity, deadwood, fungal decay, heartwood phenolics, tree } \\
\text { resistance }\end{array}$ \\
\hline &
\end{tabular}

\section{SCHOLARONE \\ Manuscripts}


1 Phenolic compounds in Scots pine heartwood: are kelo trees a unique woody substrate?

2

3 Parvathy Venugopal ${ }^{1 *}$, Riitta Julkunen-Tiitto ${ }^{2}$, Kaisa Junninen ${ }^{3}$, Jari Kouki $^{1}$

4

$5{ }^{1}$ School of Forest Sciences, University of Eastern Finland, P.O. Box 111, 80101, Joensuu, 6 Finland

7

$8{ }^{2}$ Natural Products Research Laboratories, Department of Biology, University of Eastern

9 Finland, P.O. Box 111, 80101 Joensuu, Finland

10

${ }^{3}$ Metsähallitus Parks and Wildlife Finland, c/o University of Eastern Finland/Borealis, P.O.

Box 111, 80101, Joensuu, Finland

13

$14 *$ Corresponding author. E-mail: parvathy.venugopal@uef.fi

15

16

17

18

19

20

21

22

23

24

25 


\section{Abstract}

Deadwood quality can be a highly significant factor in determining the occurrence of deadwood-dependent organisms such as saproxylic fungi. Rare deadwood substrates that are produced only after a lengthy senescence, such as kelo trees, may have unique deadwood qualities. Using high-performance liquid chromatography (HPLC), we compared the phenolic composition of six types of Scots pine substrates; living mature trees with no fungal sporocarps, living mature trees with Phellinus pini sporocarps, fallen non-kelo trees, soon-tobe-kelo (standing), standing kelo and fallen kelo. The fungal infected living trees and fallen kelos were found to have more similarities in their phenolic composition when compared to the living and fallen trees and the standing kelos, which gets further pronounced with increasing decay. The results also highlight the uniqueness of the fungal infected living trees and the fallen kelos and illustrate a possible correlation between fungal infection and the heartwood phenolic composition of Scots pine. However, it remains unclear to what extent the differences in phenolic compositions are caused by fungal infection and fungal decomposition. We also observed a previously undocumented correlation between the phenolic groups and fire scars on the trunks of the trees. The variation in substrate quality warrants further consideration when deadwood restoration activities are planned, as the quality of the deadwood could be as equally important as the quantity.

Key-words: boreal forest, chemical diversity, deadwood, fungal decay, heartwood phenolics, substrate quality, tree resistance 


\section{Introduction}

53 Forest deadwood substrates, comprised mostly of snags, fallen dead trunks and stumps 54 (Hagemann et al. 2009), are of high ecological value as they maintain a large part of the 55 structural and biological diversity of forests (Tikkanen et al. 2006; Hottola et al. 2009). They 56 provide a habitat for numerous organisms and act as a long-term nutrient source for soil 57 detritivores (Siitonen 2001). In particular, old growth forests provide a high volume of very 58 diverse deadwood types (Siitonen 2001), some of which are rare and structurally or 1995; Niemelä et al. 2002).

Large, standing pine trees (Pinus sylvestris L.) and pine snags are common in natural oldgrowth pine forests but rarities in managed forests throughout boreal Europe. These trees have characteristic growth and death patterns (Niemelä et al. 2002). Typically, they lose their growth vigor slowly and die gradually while still standing. The death of large pines may take centuries (Rouvinen et al. 2002). During this process, the sapwood is colonized by blue-stain fungi, giving these decorticated trees a silvery grey color on the debarked surface. These trees are called 'kelo' in the Finnish language, and the usage of the word has been extended to English texts to describe similar kinds of trees. The blue-stain fungi utilize the cell contents, leaving the lignin, cellulose or hemicelluloses undecayed thereby causing no true decay but making the wood unattractive for most decay-causing fungi (Niemelä et al. 2002).

In addition to the silvery-grey debarked trunk, standing kelos are characterized by the absence of the whole crown from the standing trunk or by the presence of just a few thick branches. In most old kelos, the sapwood has decayed and worn away leaving only the 
4

76 eroded heartwood. Kelos may stay standing for several decades or even a few centuries

77 (Rouvinen et al. 2002). Old kelos have almost always experienced at least one fire episode

78 during their 'growth and death' period, sometimes resulting in a charred surface, either on the

79 outer surface or in the inner layers of the heartwood, depending on whether the fire occurred

80 during or after the death process. Niemelä et al. (2002) suggested that fungal succession,

81 fungal species diversity and the rate of decomposition are fundamentally different in kelos

82 than in old pine trees which fall while still alive, for example, during windstorms. Standing

83 trees decompose more slowly than fallen ones because their trunk is not in contact with the

84 soil and, consequently, the moisture content in the woody tissues is much lower (Yatskov et

85 al. 2003).

86

87 Kelos have considerable economic and ecological value. Although Scots pine is one of the 88 most common trees in this region (Palviainen et al. 2010), kelos are considered a 'vanishing' 89 substrate and a very slowly renewable woody material in north European boreal forests

90 (Niemelä et al. 2002). This is partly due to the slow formation of kelos, which results in 91 approximately one kelo tree per hectare in a decade (Rouvinen et al. 2002). In addition, kelos 92 are considered as an excellent and expensive raw material for buildings as a result of their 93 resistance to decay. An in-depth understanding of the chemical constitution of kelos, in

94 particular the phenolic characteristics, would be highly beneficial when seeking to increase 95 the natural durability of the wood to wood rot. From an ecological viewpoint, decay 96 resistance affects deadwood dynamics and, therefore, carbon and nutrient dynamics in forest 97 ecosystems for example. However, to the best of our knowledge, no attempts have been made 98 to analyze the chemical constitution of the kelos in comparison to live or dead non-kelo pine 99 trees. 
101 Wood extractives that reside in the lignocellulosic woody tissue consist of several chemical 102 components, such as triglycerides, steryl esters, resin acids, free fatty acids, sterols and 103 phenolic compounds, such as terpenoids, flavonoids and tannins. These compounds are considered as significant factors in contributing to the natural decay resistance of the heartwood extractive content (Taylor et al. 2003).

Recent studies have elaborated on the chemical composition of living Scots pine heartwood (e.g., Ekeberg et al. 2006), although little information is available on kelos. Scots pine heartwood predominantly contains two positively correlated phenolic secondary compounds (i.e. phenolics): pinosylvin (PS) and pinosylvin monomethyl ether (PSM) that belong to the 'stilbene' group (e.g., Harju et al. 2002, Venäläinen et al. 2004). These phenolics are known to be formed during heartwood production or as an active defence response to fungal infection (e.g., Delorme and Lieutier, 1990; Nagy et al. 2005) or injury (producing phenolics such as phytoalexins; Heijari et al. 2005). The phenolics seem to exhibit toxicity and to give low hygroscopicity to the heartwood (Celimene et al. 1999), possibly inhibiting fungal decay (Karppanen et al. 2008). However, fungal infection may also alter the capacity of the trees to produce secondary compounds (Bois et al. 1997). Furthermore, whether these fungal infection-induced changes in the phenolic content in Scots pine heartwood also hold for kelos has yet to be established. Previous studies have also found that fire scarred trees have an increased pre-disposition towards fungal attack (Geiszler et al. 1980) as a result of reduced health. Niemelä et al. (2002) have stated that kelos survive several fires in their history. 
127 Previous studies have indicated that the concentration of total phenolics and stilbenes could 128 be used as an indirect measure of heartwood durability against decay (Heijari et al. 2005; 129 Harju and Venäläinen 2006). However, the presence of stilbenes alone cannot explain the 130 defence against fungal decay, as their chemical action and mechanism still needs to be 131 studied in detail (Hart and Shrimpton 1979; Venäläinen et al. 2004).

132

133 This study examines the variation of phenolics in the heartwood of six different types of coarse woody substrates of Scots pine, including kelo. We hypothesized that kelos are likely to be rich in secondary phenolics that are otherwise not present in live or recently killed pines because of a lengthy death process. In addition, we hypothesized that fungal attack may contribute to an alteration in the heartwood chemistry. We also hypothesized that a trend could be observed in heartwood phenolic composition during the transition of the tree from living to fungal-infected to dead, and from partially to fully dead kelo.

Although the impact of fire on the phenolic composition was considered in the analyses, as many of the sampled trees had fire scars on their trunks, it was not planned in the original sample selection and led to an asymmetrical dataset. However, we anticipated that since fires often damage trees and obviously modify the slow death process of pines, fires may also have some effect on the chemical characteristics of old pine trees and kelos. 
150 Wood samples were obtained from the Patvinsuo National Park in Lieksa and Ilomantsi in 151 Northern Karelia, eastern Finland $\left(63^{0} 07^{\prime}\right.$ N, $\left.30^{\circ} 45^{\prime} \mathrm{E}\right)$. The region is located in the middle boreal zone. Scots pine is the dominant tree species. For this study, six different Scots pine tree types were included (listed in detail in Table 1 and Fig. 1).

\section{WOOD SAMPLE EXTRACTION AND PREPARATION}

\section{EXTRACTION AND ANALYSIS OF PHENOLICS}

172 The heartwood samples $(8 \mathrm{mg})$ were milled and the powdered residue was extracted with 0.6 $173 \mathrm{ml}$ of cold methanol (100\%) for $25 \mathrm{sec}$ using a Precellys ${ }^{\circledR} 24$ homogenizer (Bertin 174 Technologies, Île-de-France, France). After standing for $15 \mathrm{~min}$. in an ice bath, they were 
175 homogenized for a second time for $25 \mathrm{sec}$ and then centrifuged (Eppendorf® Centrifuge 176 5415R, Hamburg, Germany) at $13,000 \mathrm{rpm}$ for $3 \mathrm{~min}$. at $+4^{\circ} \mathrm{C}$ and the methanol supernatant 177 separated. The residue was extracted three more times using the same process, and with a 178 reduced 5 min. standing time in the ice bath. The multiple supernatants were combined and 179 the methanol evaporated to dryness by using an Eppendorf® concentrator (Hamburg, 180 Germany). The dried samples were stored at $-20^{\circ} \mathrm{C}$ until analyzed by the high-performance 181 liquid chromatography (HPLC) as described by Randriamana et al. (2014). Prior to analysis, 182 the samples were dissolved in $300 \mu \mathrm{l}$ milli-Q water (Merck Millipore, Darmstadt, Germany): 183 methanol (50:50, v/v), then centrifuged at 13,000 rpm for 3 minutes. coefficient of eriodictyol. of-flight mass spectrometer (Q/TOF-MS) (6340 series, Agilent) was used to identify the compounds. The Q/TOF-MS spectra collected at ESI positive ion mode with the following parameters: mass range $100-3000 \mathrm{~m} / \mathrm{z}$; temperature of the drying gas and sheath gas $350{ }^{\circ} \mathrm{C}$; 
9

200

201

202

203

204

205

206

207

208

209

210

211

212

213

214

215

216

217

218

219

220

221

222

223

nozzle voltage $1000 \mathrm{~V}$; fragmentor voltage $80 \mathrm{~V}$; skimmer voltage $65 \mathrm{~V}$ and octopole voltage $750 \mathrm{~V}$. The mass-to-charge ratio value of 922.0098 was used as a reference for accurate mass measurements. The mass accuracy/error term (in ppm) was calculated based on the equation; $\left[\mathrm{M}_{\text {measured }}\right.$ (monoisotopic calculated mass) $-\mathrm{M}_{\text {calculated }}$ (accurate mass) $\left.\} \times 10^{6}\right] / \mathrm{M}_{\text {calculated }}$ (accurate mass).

ToF-MS provides accurate mass measurement with a mass accuracy range close to 2-5 ppm with an adequate calibration range (Lacorte and Fernandez-Alba, 2006). We calculated the monoisotopic mass of the compounds based on KEGG database (2014). The compounds identified with UPLC-DAD-MS are listed in Table 2.

\section{STATISTICS}

The differences in the mean concentration among substrates were compared using ANOVA (SPSS Version 21.0). In addition, multivariate ordination was applied using Non-Metric multi-Dimensional Scaling (NMDS) in PC-ORD Version 5.0 (McCune and Mefford, 1999) to analyze the possibility of distinct chemical groups in the six tree substrate categories.

\section{Results}

In total, we identified 48 chemical compounds (Table 3 ) from the 38 pine wood samples, based on the retention times and spectral characteristics of the compounds. The main phenolic groups were stilbenes $\left(\mathrm{St}_{1-10}\right.$, including PS, PSM, resveratrol, methyl resveratrol, methyl piceatannol and one stilbene derivative (other than pinosylvin group)), neolignans $\left(\mathrm{NL}_{1-7}\right)$, lignans $\left(\mathrm{L}_{1-12}\right)$, vanillic acid derivatives $\left(\mathrm{VA}-\mathrm{d}_{1-5}\right)$, cinnamic acid derivative (CA-d), 
224 ferulic acid derivatives $\left(F A-\mathrm{d}_{1-4}\right)$, naringenin derivatives $\left(\mathrm{NG}-\mathrm{d}_{1-3}\right)$ and eriodictyol 225 derivatives $\left(\right.$ ER-d $\left.\mathrm{d}_{1-6}\right)$.

227 The stilbenes (Table 2) were identified using mass spectrometry. The high precision of the spectrometry (3.78-9.33 ppm) suggests we can accurately determine the chemical structure of secondary compounds.

Among the recorded phenolic compounds, 24 out of the 48 were found to differ between the tree types (Table 3). Different trees in the sample population exhibited different spectral chromatograms. The chromatograms of the representative trees from each tree type indicating the most important differences in the spectral signatures are presented in Fig. 3. Overlapping of the spectral absorbance peaks were noticeably more common in samples from 'living with fungi' and 'partial kelo'.

Although living trees, fallen non-kelos and the standing kelos did not exhibit significant differences in their overall phenolic chemistry (pair-wise post-hoc comparisons, Fig. 2a), noticeable differences were found in their chromatograms. Most of the trees in naturally fallen non-kelo tree group exhibited fewer phenolic compounds on the chromatogram (for example Fig. 3c), compared to the living mature trees (Fig. 3a). Concentrations of PS and PSM compounds were high in all tree types except in a few individuals of 'living with fungi' with advanced heart rot, in which an unidentified stilbene derivative $\left(\mathrm{ST}_{3}\right)$ showed the highest phenolic concentration (Fig. 3b). . Most of the fallen kelos (for example Fig. 3f) exhibited higher incidence of phenolics compared to the partial kelo tree samples (Fig. 3d) and standing kelos samples (Fig. 3e). There was a general similarity between the fungal infected living trees and fallen kelos in the overall phenolic structure, and in most of the specific phenolic 
11

groups (except for VA-d, Fig. 2e). These two groups often differed from the living trees in regard to overall heartwood phenolics (Fig. 2a), as well as in all the specific phenolic groups (Figs 2 b, c, d, g, h, and i), with the exception of lignans (Fig. 2d) and CA-d (Fig. 2f).

In the NMDS analysis, the heartwood phenolic compounds concentration data of the different tree samples was run with random starting coordinates. After 94 iterations, the analyses identified a two-dimensional solution (as additional dimensions did not lower the stress value) with a final stress value 8.13878 and final instability 0.000010 . No conclusive grouping was evident among the tree categories in the NMDS plot (Fig. 4). However, the fungal-infected living trees and the fallen kelos that were in the more advanced decay stage (expressed in terms of the disintegrated heartwood core) tended to be the furthest from their counterparts. Similarly, the four standing kelos that exhibited more advanced decay were also located away from the other members of this group in the NMDS plot. When the fire-scarred samples were analyzed separately, the trees with fire scars tended to separate in their overall chemical composition from the remaining trees (Fig. 5a). The phenolics; VA-d $\mathrm{d}_{1}, \mathrm{VA}-\mathrm{d}_{4}, \mathrm{VA}-$ $\mathrm{d}_{5}, \mathrm{NL}_{1}, \mathrm{NL}_{2}, \mathrm{NL}_{5}, \mathrm{~L}_{1}, \mathrm{~L}_{7}, \mathrm{NA}-\mathrm{d}_{1}$ and ST-d, were found to be associated with the grouping of the trees with fire scars (Fig. 4; Fig. 5a).

\section{Discussion}

Despite their unique formation and attributes, heartwood from the three categories of kelos did not exhibit sufficient differences in their phenolic chemistry to establish distinct groupings from one another in the NMDS plot, or from the heartwoods of other tree groups analyzed. But decaying heartwood from fallen kelo did sort away from the other two kelo 
274 groups, while the heartwood from fungal-infected living trees sorted away from heartwood of 275 most other tree groups in the NMDS plot. Furthermore, the four standing kelo trees with the 276 most advanced decay sorted more closely to the decaying fungal-infected trees and fallen

277 kelo, whereas the four with less decayed heartwood sorted with the healthy, live trees and 278 fallen non-kelo. This NMDS sorting of trees with advanced decay in conjunction with the 279 overlap of living trees with the fallen healthy trees seems to imply that the dynamics involved 280 in the decay of the latter group may be difference from the fungal-infected living trees and 281 fallen kelo. There were notable outliers in the NMDS plot, especially in the fallen kelo and 282 fungal-infected living trees, probably a result of sample heterogeneity as the exact age, time 283 of death, and the length of time fallen kelo were in contact with the ground are not known. 284 Also, chemical changes associated with the fire might contribute to this variability, especially 285 in the fallen kelo group as discussed later.

287 Decaying heartwood from fallen kelo and fungal-infected living trees contained similar amounts of total phenolics and major compounds such as total stilbenes, PS and PSM, but at statistically lower concentrations than the healthy heartwood from living trees. The PS concentrations in living-infected trees was lower than in living trees, but not statistically lower. The other tree groups with less decayed heartwoods contained similar quantities of 292 these compounds as the live trees. Karppanen et al. (2008) measured rapid concentration 293 declines of both PS and PSM with increasing mass loss of Scots pine heartwood decayed by the brown-rot Coniophora puteana. They concluded this fungus was capable of eliminating these two compounds, even though they have been identified as playing a major part in heartwood decay resistance (e.g., Venäläinen et al. 2004; Harju et al. 2009). This

297 interpretation fits our observations here as well. Other notable chemical differences include 298 VA-d with higher concentrations in living trees with Phellinus pini sporocarps, in which the 
heartwood had mostly disintegrated followed by fallen kelo and standing kelo types (Fig. 2e).

300 This suggests a possible correlation between advancing fungal infestation and VA-d production. Then there is Fa-d which was similar in all the groups except in living trees with no visible fungal attack, where it was strikingly higher (Fig. 2g). The role of all these compounds in fungal decay or resistance can be explored further. .

Phenolic compounds have been previously linked to defence mechanisms of plants against natural enemies, such as fungal pathogens (Hammerschmidt 2003). However, no consistent conclusive evidence has come up confirming the relationship between phenolics and the resistance of trees to pathogens from previous literature (Witzell and Martín 2008). Our findings give rise to few possibilities: Instead of directly attributing to the tree resistance, these phenolics especially the minor ones may act as precursors for other defensive compounds or may act as a group rather than as individual compounds. Since marked differences between living trees and standing kelos were not observed, it is also possible that the heartwood phenolics could be complemented by other defensive metabolites such as terpenoids or defensive proteins. This could help us to understand the 'possible [ecological] uniqueness of kelos' (Niemelä et al. 2002). However both these theories require further investigation.

The segregation of the trees with and without fire scars in the ordination plot was rather clear, although this aspect was not directly included in the original sampling plan. Thus, due to the scarcity of data, we do not have conclusive evidence to prove that fire plays a role in the formation of kelo chemistry. However, it was interesting to note that the trees in the 'living' and 'living with Phellinus pini fruiting bodies' type with fire scars tend to resemble those

323 kelos that have charred trunks. The grouping of the samples in the NMDS plot was highly 
324 correlated to axis $2\left(\mathrm{R}^{2}=.902\right)$, denoting the environmental variable 'presence/absence of fire

325 scar' and indicating the role of fire in the phenolic chemistry and its transition in the different

326 substrates. Furthermore, most of the phenolics (except for higher concentration of neolignans

327 and more or less similar concentration of stilbenes, other than PS and PSM) were

328 comparatively less abundant in the fire scarred trees (Fig. 5b). Earlier, Harju et al. (2008)

329 showed that the concentration of resin acids, stilbenes and lignans increased when injury was

330 induced to the xylem in Scots pine. Quite contrary to this, our results indicate that overall

331 phenolic concentration was lower in fire scarred individuals.

332

333 The absence of sufficient differences in phenolic chemistry between living trees and standing

334 kelos contradicts our initial hypothesis that the apparent uniqueness of kelos can be explained

335 by secondary phenolics. Our results indicated fungal infestation and fire having notable effect

336 on the phenolic composition of the deadwood, in accordance with our second hypothesis. It is

337 highly likely that this also affects the decomposition rate of the woody tissues. . However, our

338 results suggested that the chemical distinctiveness among the living tree groups and the kelo

339 groups were limited and it became evident only in stages of tree death and advanced decay.

340 This supports our third hypothesis that the woody phenolic composition changes when a tree

341 advances from one growth or decay stage to another. Despite our new findings, there are still

342 wide gaps in our understanding of extractive formation and their dependence on

343 environmental factors, tree growth (especially radial growth), and silvicultural practices such

344 as thinning. A better assessment of these relationships would provide more information in

345 regard to the manipulation of artificial kelo formation and wood quality, and also for

346 understanding the decomposition dynamics of the trees in forest ecosystems. 
349

350

351

352

353

354

355

356

357

358

359

360

361

362

363

364

365

366

367

368

369

370

371

372

373

\section{Acknowledgements}

This study was funded by the Maj and Tor Nessling Foundation (project 2014530, grant to author Jari Kouki) We thank Jarmo Pennala at the School of Forest Sciences, University of Eastern Finland, for his invaluable assistance in the field work. We extend our gratitude to the Natural Products Research Laboratories, Department of Biology, University of Eastern Finland and its staff, Sinikka Sorsa, Katri Nissinen, Tendry R. Randriamanana, Anu Lavola and Anneli Salonen for their timely guidance and assistance in the laboratory. We thank Hannes Pasanen for his involvement in the study.

\section{References}

Bois, E., Lieutier, F., Sauvard, D. and Yart, A. 1997. Phenolic and Resistance of Scots Pine to Bark Beetles. Proceedings: Integrating cultural tactics into the management of bark beetle and reforestation pests. USDA For. Serv. G.T.R. NE-236: 92-94. Available from http://iufro-archive.boku.ac.at/wu70307/valproc/bois.pdf [accessed on 30 July 2014].

Celimene, C. C., Micales, J. A., Ferge, L., and Young, R. 1999. Efficacy of pinosylvins against white-rot and brown-rot fungi. Holzforschung 53: 491-497.

Delorme, L. and Lieutier, F. 1990. Monoterpene composition of the preformed and induced resins of Scots pine and their effect on bark beetles and associated fungi. Eur. J. For. Pathol. 20: 304-316. doi: http://dx.doi.org/10.1111/j.1439-0329.1990.tb01142.x.

Eberhardt, T. L., Han, J. S., Micales, J. A. and Young, R. A. 1994. Decay Resistance in Conifer Seed Cones: Role of Resin Acids as Inhibitors of Decomposition by White-Rot Fungi. Holzforschung, 48: 278-284. doi: 10.1515/hfsg.1994.48.4.278.

Ekeberg, D., Flæte, P. O., Eikenes, M., Fongen, M. and Naess-Andresen, C. D. 2006. Qualitative and quantitative determination of extractives in heartwood of Scots pine 
(Pinus sylvestris L.) by gas chromatography. J. Chromatogr. A. 1109: 267-272. doi:10.1016/j.chroma.2006.01.027.

Geiszler, D. R., Gara, R. I., Driver, C. H., Gallucci, V. F. and Martin, R. E. 1980. Fire, fungi, and beetle influences on a lodgepole pine ecosystem of south-central Oregon. Oecologia, 46, 239-243.

Hagemann, U., Moroni, M.T. and Makeschin, F. 2009. Deadwood abundance in Labrador high-boreal black spruce forests. Can. J. For. Res. 39: 131- 142. doi: 10.1139/X08-166.

Hammerschmidt, R. 2003. Defense responses: in the orchard and the forest. Physiol. Mol. Plant Pathol. 63: 235-236. doi: 10.1016/j.pmpp.2004.05.001.

Harju, A. M., Kainulainen, P., Venäläinen, M., Tiitta, M. and Viitanen, H. 2002. Differences in resin acid concentration between brown-rot resistant and susceptible Scots pine heartwood. Holzforschung, 56: 479-486. doi: 10.1515/HF.2002.074.

Harju, A. M. and Venäläinen, M. 2006. Measuring the decay resistance of Scots pine heartwood indirectly by the Folin-Ciocalteu assay. Can. J. For. Res. 36: 1797-1804. doi: 10.1139/x06-074.

Harju, A. M., Venäläinen, M., Laakso, T. and Saranpää, P. 2009. Wounding response in xylem of Scots pine seedlings shows wide genetic variation and connection with the constitutive defence of heartwood. Tree Physiol. 29: 19-25. Available from http://treephys.oxfordjournals.org/content/29/1/19.full [accessed 25 September 2011].

Hart, J. H and Shrimpton, D. M. 1979. Role of Stilbenes in resistance of wood to decay. Phytopathology, 69: 1138-1143. Available fromhttp://www.apsnet.org/publications/ phytopathology/backissues/Documents/1979Abstracts/Phyto69_1138.htm [accessed 14 July 2014].

Heijari, J., Nerg, A. M., Kaakinen, S., Vapaavuori, Elina., Raitio, H., Levula, T., Viitanen, H., Holopainen, J. K. and Pirjo, K. 2005. Resistance of Scots pine wood to Brown-rot 
17

399

400

401

402

403

404

405

406

407

408

409

410

411

412

413

414

415

416

417

418

419

420

421

fungi after long-term forest fertilization. Trees, 19: 728-734. doi: 10.1007/s00468-0050035-1.

Hottola, J., Ovaskainen, O., and Hanski, I. 2009. A unified measure of the number, volume and diversity of dead trees and the response of fungal communities. J. Ecol. 97: 1320 1328. doi:10.1111/j.1365-2745.2009.01583.x.

Jorgensen, E. 1961. The formation of Pinosylvin and its monomethyl ethers in the sapwood of Pinus resinosa Ait. Botany. 39: 1765-1772. doi: 10.1139/b61-155.

Karppanen, O., Venäläinen, M., Harju, A., and Laakso, T. 2008. The effect of brown-rot decay on water adsorption and chemical composition of Scots pine heartwood. Annals of Forest Science 65(6): 610-610. doi: 10.1051/forest:2008035.

Komenda, M. and Koppmann, R. 2002. Monoterpene emissions from Scots pine (Pinus sylvestris): field studies of emission rate variabilities. J. Geophys. Res. 107. doi: 10.1029/2001JD000691.

Laboratories, Kanehisa. 2014. KEGG: Kyoto Encyclopedia of Genes and Genomes. doi: http://www.genome.jp/kegg/.

Lacorte, S. and Fernandez-Alba, A. R. 2006. Time of flight mass spectrometry applied to the liquid chromatographic analysis of pesticides in water and food. Mass Spectrom. Rev. 25: 866- 880. doi:10.1002/mas.20094.

McCune, B. and Mefford, M. J. 1999. PC-ORD. Multivariate Analysis of Ecological Data, Version 4. MjM Software Design, Gleneden Beach, Oregon, USA.

Nagy, N. E., Krokene, P. and Solheim, H. 2005. Anatomical-based defense responses of Scots pine (Pinus sylvestris) stems to two fungal pathogens. Tree Physiol. 26: 159-167. doi: 10.1093/treephys/26.2.159. 
422 Niemelä, T., Renvall, P. and Penttilä, R. 1995. Interactions of fungi at late stages of wood 423 decomposition. Ann. Bot. Fennici, 32: 141-152. Available from www.jstor.org/stable/ 42423726315 [accessed 10 September 2013].

425 Niemelä T., Wallenius T. and Kotiranta H. 2002. The kelo tree, a vanishing substrate of 426 specified wood-inhabiting fungi. Polish Bot. J. 47: 91-10. Available from 427 bomax.botany.pl/pubs/data/article_pdf?id=763[accessed 5 September 2011].

428 Nilsson, M., Wikman, S. and Eklund, L. 2002. Induction of discolored wood in Scots pine 429 (Pinus sylvestris). Tree Physiol. 22: 331-338. doi: 10.1093/treephys/22.5.331.

430 Palviainen, M., Finér, L., Laiho, R., Shorohova, E., Kapitsa, E. and Vanha-Majamaa, I. 2010. 431 Carbon and Nitrogen release from decomposing Scots pine, Norway spruce and silver 432 birch stumps. For. Ecol. Manage. 259: 390-398. doi:10.1016/j.foreco.2009.10.034.

433 Randriamanana, T. R., Nybakken, L., Lavola, A., Aphalo, P. J., Nissinen, K. and Julkunen434 Tiitto, R. 2014. Sex-related differences in growth and carbon allocation to defence in 435 Populus tremula as explained by current plant defence theories. Tree Physiol. 34: 471$436 \quad$ 487. doi:10.1093/treephys/tpu034.

437 Renvall, P. 1995. Community structure and dynamics of wood-rotting Basidiomycetes on 438 decomposing conifer trunks in northern Finland. Karstenia, 35: 1-51.

439 Rouvinen, S., Kuuluvainen, T. and Siitonen, J. 2002. Tree mortality in a Pinus sylvestris 440 dominated boreal forest landscape in Vienansalo wilderness, eastern Fennoscandia. Silva 441 Fenn. 36: 127-145. Available from http://www.metla.fi/silvafennica/abs/sa36/sa361127 $442 \quad$.htm [accessed on 15 September 2014].

443 Siitonen, J. 2001. Forest management, coarse woody debris and saproxylic organisms: 444 Fennoscandian boreal forests as an example. Ecol. Bull. 49: 11-41. doi: 10.2307/ $445 \quad 20113262$. 
446 Taylor, A. M., Gartner, B. L. and Morrell, J. 2003. Co-incident variations in growth rate and 447 heartwood extractive concentration in Douglas-fir. For. Ecol. Manage. 186: 257-260. 448 doi:10.1016/S0378-1127(03)00278-0.

449 Tikkanen, O.-P., Martikainen, P., Hyvärinen, E., Junninen, K., and Kouki, J. 2006. Red-listed 450 boreal forest species of Finland: associations with forest structure, tree species, and 451 decaying wood. Annales Zoologici Fennici 43: 373-383.

452 Vanderwel, M. C., Malcolm, J. R. and Smith, S. M. 2006. An integrated model for snag and 453 downed woody debris decay class transitions. For. Ecol. Manage. 234: 48-59. 454 doi:10.1016/j.foreco.2006.06.020.

455 Venäläinen, M., Harju, A. M., Saranpää, P., Kainulainen, P., Tiitta, M. and Velling, P. 2004. 456 The concentration of phenolics in brown-rot decay resistant and susceptible Scots pine 457 heartwood. Wood Sci. Technol. 38: 109-118. doi: 10.1007/s00226-004-0226-8.

458 Witzell, J. and Martín, J. A. 2008. Phenolic metabolites in the resistance of northern forest 459 trees to pathogens - past experiences and future prospects. Can. J. For. Res. 38: 2711$460 \quad$ 2727. doi: $10.1139 / \mathrm{X} 08-112$.

461 Yatskov, M., Harmon, M. E. and Krankina O. N. 2003. A chronosequence of wood 462 decomposition in the boreal forests of Russia. Can. J. For. Res. 33: 1211-1226. doi: $463 \quad 10.1139 / \mathrm{x} 03-033$. 
Table 1. Features of the different Scots pine tree types (Fig. 1.) used in the study

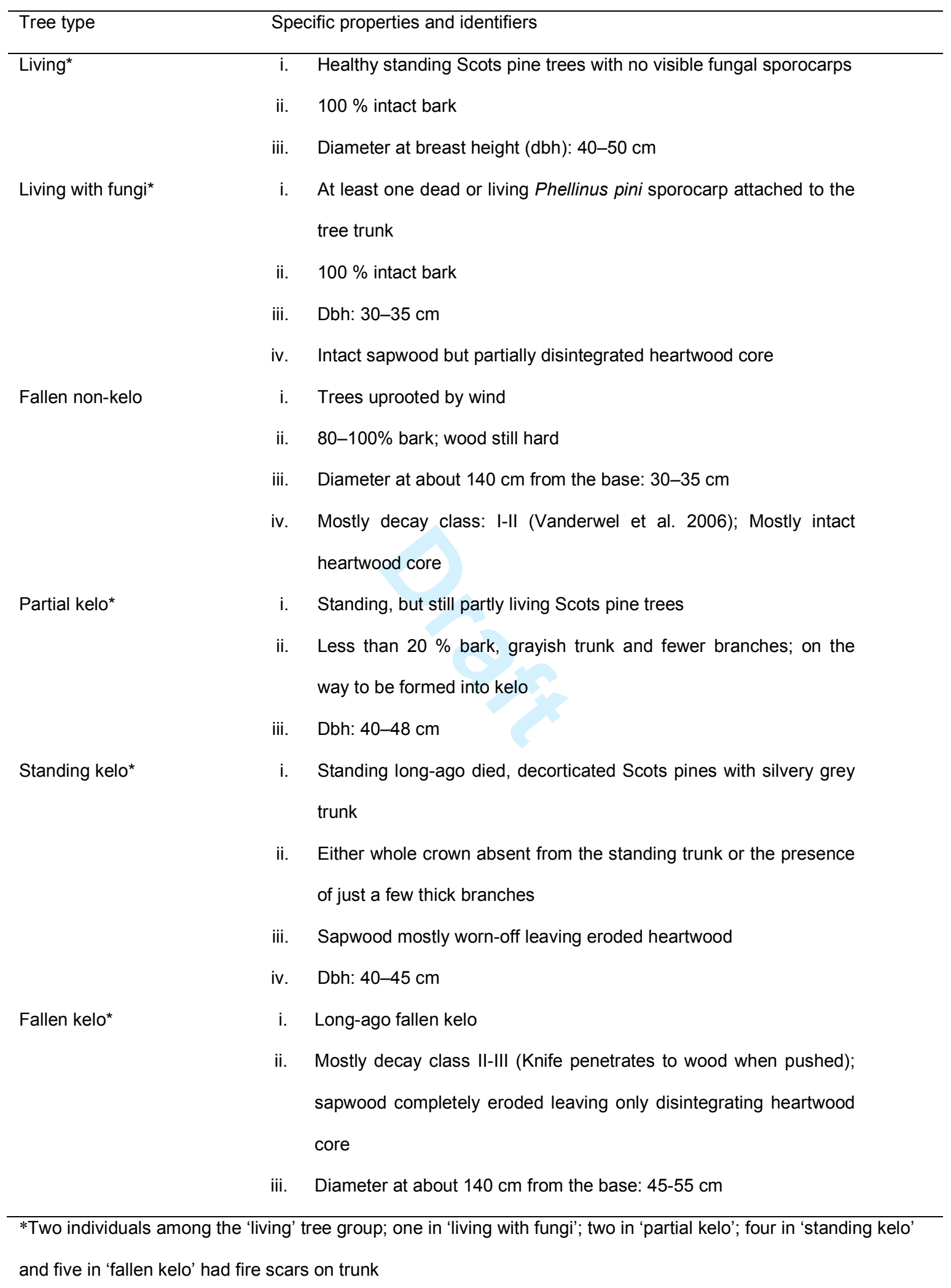


Table 2. Mass accuracy (or error term) of the phenolic compounds identified through UPLC-DAD-MS.

\begin{tabular}{lllll}
\hline $\begin{array}{l}\text { Stilbene } \\
\text { proposed }\end{array}$ & Identified & $\begin{array}{l}\text { M } \\
\text { coasured }\end{array}$ & $\begin{array}{l}\text { Mcalculated } \\
\text { (Monoisotopic mass) }\end{array}$ & $\begin{array}{l}\text { (Accurate mass) } \\
\text { (in ppm) }\end{array}$ \\
\hline stilbene $_{1}$ & PS & 211.0769 & 212.0758 & 5.07 \\
stilbene $_{2}$ & PSM & 225.0936 & 226.0994 & 9.33 \\
stilbene $_{4}$ & Resveratrol & 227.0719 & 228.0786 & 5.23 \\
stilbene $_{5}$ & Methyl Resveratrol & 241.0877 & 242.0943 & 5.57 \\
stilbene $_{6}$ & Methyl Piceatannol & 257.0823 & 258.0892 & 3.78 \\
\hline
\end{tabular}


Table 3. Concentration (Means \pm 1 S.E.) of the individual and total phenolics (mg/g dry wood weight) present in the heartwood of different Scots pine tree types $\mathrm{F}$ - and pvalues are based on one-way ANOVA. Asterisks (*) denote $P$-values: ${ }^{*} p<0.05$; ${ }^{* *} p<0.01$.

\begin{tabular}{|c|c|c|c|c|c|c|c|c|c|c|}
\hline $\begin{array}{l}\text { Phenolic } \\
\text { Groups }\end{array}$ & $\begin{array}{c}\text { Serial } \\
\mathrm{Nr} .\end{array}$ & Phenolics & $\begin{array}{l}\text { Living } \\
(n=8)\end{array}$ & $\begin{array}{l}\text { Living with fungi } \\
\qquad(\mathrm{n}=7)\end{array}$ & $\begin{array}{l}\text { Fallen non-kelo } \\
\qquad(\mathrm{n}=5)\end{array}$ & $\begin{array}{l}\text { Partial kelo } \\
(n=5)\end{array}$ & $\begin{array}{l}\text { Standing kelo } \\
\qquad(\mathrm{n}=8)\end{array}$ & $\begin{array}{l}\text { Fallen kelo } \\
\qquad(n=5)\end{array}$ & F-value & $P$-value \\
\hline \multirow{11}{*}{ Stilbene } & 1 & $\mathrm{ST}_{1}$ & $2.79 \pm .73$ & $0.98 \pm .28$ & $3.13 \pm .42$ & $3.14 \pm 1.84$ & $1.44 \pm .30$ & $0.34 \pm .16$ & 2.399 & .059 \\
\hline & 2 & $\mathrm{ST}_{2}$ & $7.04 \pm 1.45$ & $1.72 \pm .47$ & $7.43 \pm 1.58$ & $8.85 \pm 3.22$ & $5.32 \pm .80$ & $1.50 \pm .67$ & 4.056 & $.006^{*}$ \\
\hline & 3 & $\mathrm{ST}_{3}$ & 0 & $0.49 \pm .26$ & 0 & 0 & 0 & $0.01 \pm .01$ & 3.167 & $.020^{*}$ \\
\hline & 4 & $\mathrm{ST}_{4}$ & $0.02 \pm .01$ & $0.07 \pm .03$ & $0.001 \pm .00$ & $0.01 \pm .00$ & $0.004 \pm .00$ & $0.01 \pm .01$ & 2.555 & $.047^{\star}$ \\
\hline & 5 & $\mathrm{ST}_{5}$ & 0 & $0.09 \pm .02$ & 0 & 0 & 0 & 0 & & \\
\hline & 6 & $\mathrm{ST}_{6}$ & 0 & 0 & 0 & 0 & 0 & $0.05 \pm .09$ & & \\
\hline & 7 & $\mathrm{ST}_{7}$ & $0.03 \pm .03$ & $0.12 \pm .04$ & $0.03 \pm .01$ & $0.12 \pm .05$ & $0.06 \pm .01$ & $0.04 \pm .02$ & 2.017 & .103 \\
\hline & 8 & $\mathrm{ST}_{8}$ & 0 & $0.02 \pm .01$ & 0 & 0 & 0 & 0 & & \\
\hline & 9 & $\mathrm{ST}_{9}$ & $0.18 \pm .03$ & $0.04 \pm .01$ & $0.14 \pm .03$ & $0.23 \pm .07$ & $0.14 \pm .03$ & $0.05 \pm .02$ & 4.525 & $.003^{*}$ \\
\hline & 10 & ST-d & $0.33 \pm .19$ & $0.32 \pm .29$ & $0.06 \pm .02$ & $0.40 \pm .29$ & $1.71 \pm 1.00$ & $0.84 \pm .30$ & 1.259 & .306 \\
\hline & \multicolumn{2}{|r|}{ Total } & $10.38 \pm 2.04$ & $3.85 \pm .98$ & $10.79 \pm 2.05$ & $12.75 \pm 5.43$ & $8.67 \pm .77$ & $2.83 \pm .82$ & 3.172 & $.028^{*}$ \\
\hline \multirow{8}{*}{ Neolignan } & 11 & $\mathrm{NL}_{1}$ & $0.44 \pm .17$ & $0.09 \pm .09$ & $0.07 \pm .07$ & $0.66 \pm .35$ & $0.80 \pm .43$ & $0.18 \pm .14$ & 1.263 & .304 \\
\hline & 12 & $\mathrm{NL}_{2}$ & 0 & 0 & 0 & $0.04 \pm .02$ & 0 & $.031 \pm .02$ & 4.034 & $.006^{*}$ \\
\hline & 13 & $\mathrm{NL}_{3}$ & 0 & 0 & $0.01 \pm .01$ & $0.08 \pm .05$ & $0.04 \pm .02$ & $0.01 \pm .01$ & 5.749 & $.001^{* \star}$ \\
\hline & 14 & $\mathrm{NL}_{4}$ & $0.07 \pm .01$ & $0.02 \pm .010$ & $0.03 \pm .01$ & $0.05 \pm .01$ & $0.04 \pm .01$ & $0.02 \pm .01$ & 5.501 & $.001^{*}$ \\
\hline & 15 & $\mathrm{NL}_{5}$ & $0.20 \pm .05$ & $0.01 \pm .01$ & $0.03 \pm .02$ & $0.10 \pm .03$ & $0.08 \pm .02$ & $0.13 \pm .05$ & 4.890 & $.002^{*}$ \\
\hline & 16 & $\mathrm{NL}_{6}$ & $0.05 \pm .01$ & 0 & $0.04 \pm .01$ & $0.05 \pm .02$ & $0.04 \pm .01$ & $0.02 \pm .01$ & 3.563 & $.011^{*}$ \\
\hline & 17 & $\mathrm{NL}_{7}$ & $0.49 \pm .11$ & $0.20 \pm .06$ & $0.52 \pm .13$ & $0.74 \pm .13$ & $0.53 \pm .10$ & $0.15 \pm .05$ & 4.366 & $.004^{*}$ \\
\hline & \multicolumn{2}{|r|}{ Total } & $1.27 \pm .20$ & $0.31 \pm .11$ & $0.70 \pm .17$ & $1.65 \pm .55$ & $1.45 \pm .37$ & $0.55 \pm .13$ & 3.549 & $.012^{*}$ \\
\hline \multirow{8}{*}{ Lignan } & 18 & $\mathrm{~L}_{1}$ & 0 & 0 & $0.04 \pm .03$ & 0 & 0 & $0.20 \pm .17$ & 1.815 & .138 \\
\hline & 19 & $\mathrm{~L}_{2}$ & $0.06 \pm .00$ & 0 & $0.04 \pm .01$ & $0.01 \pm .01$ & $0.02 \pm .01$ & $0.03 \pm .02$ & 4.879 & $.002^{*}$ \\
\hline & 20 & $\mathrm{~L}_{3}$ & $0.05 \pm .00$ & 0 & $0.05 \pm .01$ & $0.05 \pm .02$ & $0.04 \pm .01$ & $0.03 \pm .03$ & 2.239 & .074 \\
\hline & 21 & $\mathrm{~L}_{4}$ & 0 & $0.02 \pm 0.01$ & $0.01 \pm .01$ & 0 & 0 & 0 & 1.548 & .203 \\
\hline & 22 & $\mathrm{~L}_{5}$ & 0 & $0.01 \pm .01$ & $0.02 \pm .01$ & $0.03 \pm .03$ & 0 & $0.03 \pm .03$ & 1.094 & .383 \\
\hline & 23 & $\mathrm{~L}_{6}$ & 0 & $0.09 \pm .04$ & $0.11 \pm .03$ & 0 & $0.004 \pm .004$ & 0 & 5.480 & $.001^{* *}$ \\
\hline & 24 & $\mathrm{~L}_{7}$ & 0 & 0 & $0.01 \pm .01$ & $0.02 \pm .02$ & 0 & 0 & 2.046 & .099 \\
\hline & 25 & $\mathrm{~L}_{8}$ & $0.05 \pm .01$ & $0.02 \pm .01$ & $0.05 \pm .01$ & $0.11 \pm .04$ & $0.11 \pm .06$ & $.01 \pm .01$ & 1.615 & .184 \\
\hline
\end{tabular}




\begin{tabular}{|c|c|c|c|c|c|c|c|c|c|c|}
\hline & 26 & $\mathrm{~L}_{9}$ & $0.10 \pm .10$ & $0.05 \pm .05$ & 0 & $0.30 \pm .11$ & $0.13 \pm .09$ & 0 & 1.446 & .235 \\
\hline & 27 & $\mathrm{~L}_{10}$ & $0.35 \pm .25$ & 0 & $0.06 \pm .02$ & $0.08 \pm .01$ & $0.08 \pm .02$ & $0.04 \pm .01$ & 1.056 & .403 \\
\hline & 28 & $\mathrm{~L}_{11}$ & $1.23 \pm 1.20$ & 0 & 0 & $0.04 \pm .01$ & $0.34 \pm 22$ & 0 & 0.670 & .649 \\
\hline & 29 & $\mathrm{~L}_{12}$ & $0.04 \pm .01$ & 0 & 0 & $0.03 \pm .00$ & $0.03 \pm .01$ & $0.02 \pm .01$ & 5.435 & $.001^{* *}$ \\
\hline & \multicolumn{2}{|c|}{ Total } & $1.88 \pm 1.56$ & $0.18 \pm .06$ & $0.39 \pm .06$ & $0.67 \pm .14$ & $0.74 \pm .32$ & $0.34 \pm .20$ & 0.621 & .685 \\
\hline \multirow{6}{*}{$\begin{array}{c}\text { Vanillic } \\
\text { acid derivatives }\end{array}$} & 30 & $V A-d_{1}$ & 0 & $0.02 \pm .01$ & $0.003 \pm .00$ & $0.003 \pm .00$ & $0.01 \pm .00$ & $0.02 \pm .01$ & 5.213 & $.001^{* *}$ \\
\hline & 31 & VA- $d_{2}$ & $0.003 \pm .001$ & $0.01 \pm .00$ & $0.01 \pm .00$ & $0.02 \pm .01$ & $0.02 \pm .01$ & $0.01 \pm .00$ & 1.670 & .170 \\
\hline & 32 & $V A-d_{3}$ & 0 & $0.10 \pm .06$ & 0 & 0 & 0 & 0 & & \\
\hline & 33 & $V A-d_{4}$ & 0 & $0.01 \pm .00$ & 0 & 0 & 0 & 0 & & \\
\hline & 34 & $V A-d_{5}$ & $0.04 \pm .01$ & $0.24 \pm .08$ & $0.01 \pm .00$ & $0.02 \pm .01$ & $0.06 \pm .03$ & $0.14 \pm .06$ & 4.608 & $.003^{*}$ \\
\hline & \multicolumn{2}{|c|}{ Total } & $0.04 \pm .01$ & $0.38 \pm .09$ & $0.03 \pm .00$ & $0.04 \pm .01$ & $0.09 \pm .03$ & $0.17 \pm .06$ & 8.308 & $.001^{* *}$ \\
\hline $\begin{array}{c}\text { Cinnamic } \\
\text { acid derivative }\end{array}$ & 35 & CA-d & $0.01 \pm .00$ & $0.02 \pm .01$ & $0.02 \pm .00$ & $0.01 \pm .00$ & $0.01 \pm .00$ & $0.01 \pm .00$ & 0.523 & 0.757 \\
\hline \multirow{5}{*}{$\begin{array}{l}\text { Ferulic acid } \\
\text { derivatives }\end{array}$} & 36 & $F A-d_{1}$ & $0.01 \pm .00$ & 0 & $0.01 \pm .01$ & $0.003 \pm .01$ & 0 & 0 & 2.416 & .058 \\
\hline & 37 & $F A-d_{2}$ & 0 & $0.004 \pm .00$ & $0.04 \pm .01$ & $0.04 \pm .02$ & $0.03 \pm .01$ & 0 & 5.580 & $.001^{* *}$ \\
\hline & 38 & $F A-d_{3}$ & $0.06 \pm .02$ & $0.01 \pm .00$ & $0.01 \pm .00$ & $0.02 \pm .01$ & $0.02 \pm .00$ & $0.01 \pm .00$ & 4.083 & $.006^{*}$ \\
\hline & 39 & $\mathrm{FA}-\mathrm{d}_{4}$ & $0.16 \pm .03$ & 0 & 0 & 0 & 0 & 0 & & \\
\hline & \multicolumn{2}{|c|}{ Total } & $0.23 \pm .05$ & $0.01 \pm .01$ & $0.05 \pm .01$ & $0.06 \pm .02$ & $0.05 \pm .01$ & $0.01 \pm .00$ & 12.125 & $.000^{\star *}$ \\
\hline \multirow{4}{*}{$\begin{array}{l}\text { Naringenin } \\
\text { derivatives }\end{array}$} & 40 & NG-d ${ }_{1}$ & 0 & 0 & $0.02 \pm .01$ & $0.03 \pm .01$ & $0.04 \pm .01$ & $0.02 \pm .01$ & 5.860 & $.001^{\star \star}$ \\
\hline & 41 & NG-d $d_{2}$ & 0 & $0.07 \pm .03$ & 0 & 0 & 0 & 0 & & \\
\hline & 42 & NG-d $d_{3}$ & $0.17 \pm .02$ & 0 & $0.10 \pm .04$ & 0 & $0.16 \pm .02$ & 0 & 17.334 & $.000^{* *}$ \\
\hline & \multicolumn{2}{|c|}{ Total } & $0.17 \pm .02$ & $0.07 \pm .03$ & $0.11 \pm .04$ & $0.03 \pm .01$ & $0.20 \pm .02$ & $0.02 \pm .01$ & 7.518 & $.000^{* *}$ \\
\hline \multirow{7}{*}{$\begin{array}{l}\text { Eriodictyol } \\
\text { derivatives }\end{array}$} & 43 & $E R-d_{1}$ & $0.03 \pm .01$ & 0 & $0.08 \pm .04$ & 0 & $0.03 \pm .00$ & 0 & 5.208 & $.001^{* *}$ \\
\hline & 44 & $E R-d_{2}$ & $0.02 \pm .01$ & 0 & 0 & 0 & $0.03 \pm .01$ & 0 & 11.120 & $.000^{* *}$ \\
\hline & 45 & $E R-d_{3}$ & $0.05 \pm .01$ & 0 & 0 & 0 & $0.07 \pm .01$ & 0 & 23.029 & $.000^{* *}$ \\
\hline & 46 & $E R-d_{4}$ & $0.12 \pm .04$ & $0.07 \pm .02$ & 0 & 0 & $0.10 \pm .02$ & 0 & 5.112 & $.001^{*}$ \\
\hline & 47 & $E R-d_{5}$ & $0.13 \pm .02$ & $0.05 \pm .03$ & $0.12 \pm .03$ & $0.15 \pm .05$ & $0.12 \pm .02$ & $0.04 \pm .02$ & 2.354 & .063 \\
\hline & 48 & $E R-d_{6}$ & $0.04 \pm .01$ & 0 & $0.02 \pm .01$ & 0 & $0.06 \pm .01$ & 0 & 17.277 & $.000^{* *}$ \\
\hline & \multicolumn{2}{|c|}{ Total } & $0.38 \pm .06$ & $0.12 \pm .04$ & $0.22 \pm .03$ & $0.15 \pm 0.05$ & $0.41 \pm .04$ & $0.04 \pm .02$ & 10.416 & $.000^{* *}$ \\
\hline Total phenolic & $\mathrm{scor}$ & tion & $14.35 \pm 3.26$ & $4.94 \pm 1.13$ & $12.30 \pm 2.24$ & $16.04 \pm 7.71$ & $11.61 \pm 1.04$ & $3.98 \pm 1.06$ & 2.794 & $.034^{*}$ \\
\hline
\end{tabular}


Note: Compounds present in only one group of trees were not analyzed statistically. 


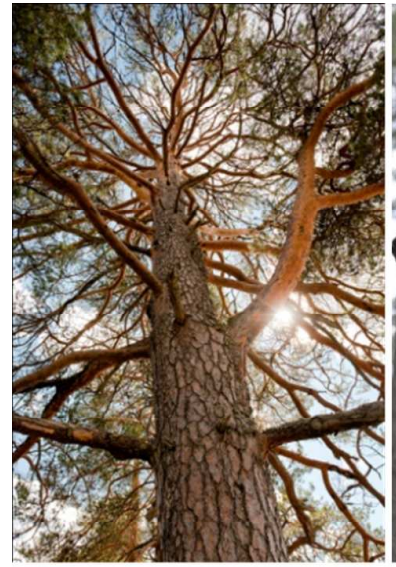

(a) Living

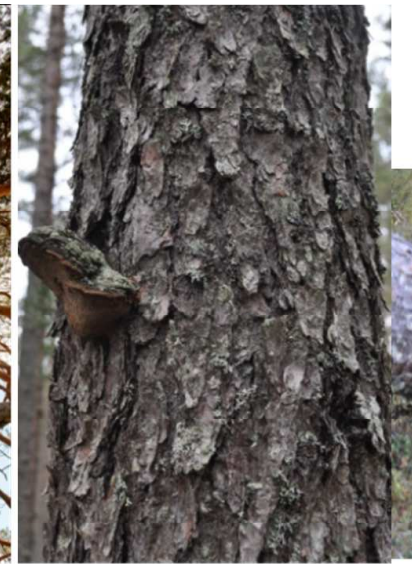

(b) Living with fungi

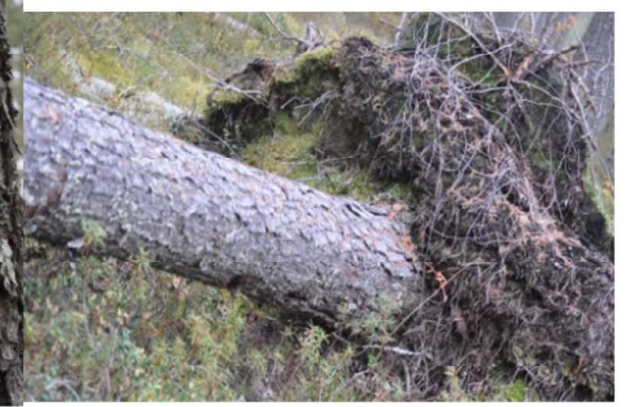

(c) Fallen non-kelo

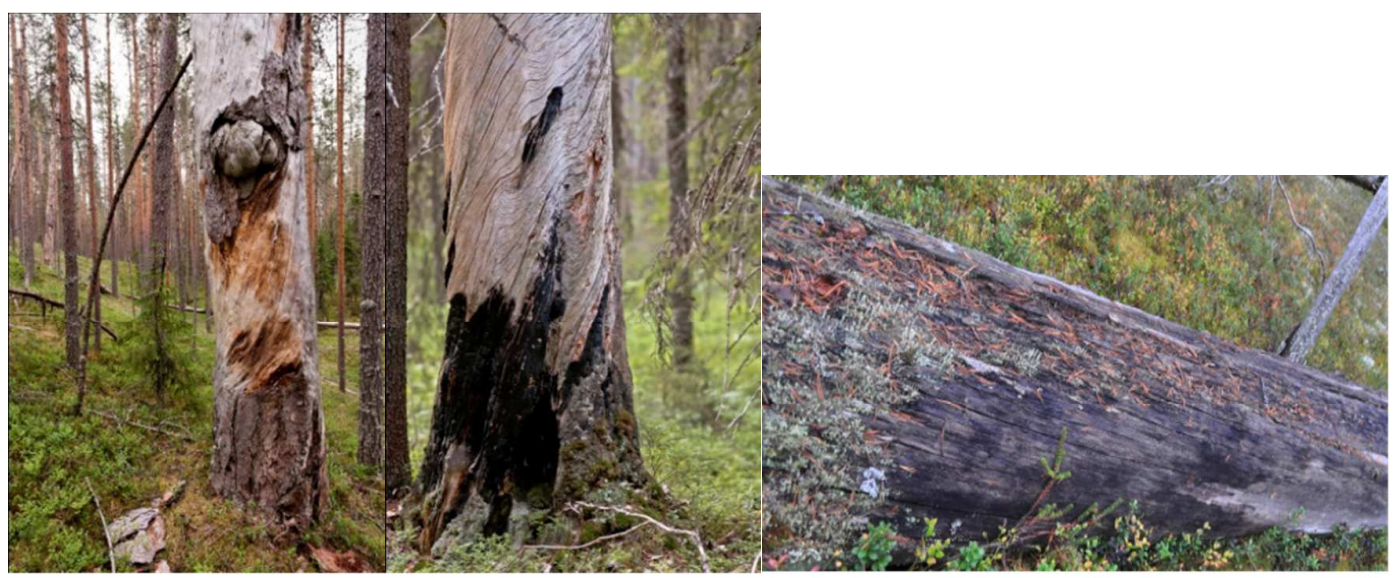

(d) Partial kelo

(e) Standing kelo

(f) Fallen kelo

Fig. 1. The Scots pine tree types included in the study (for characteristic features, see Table 1). 

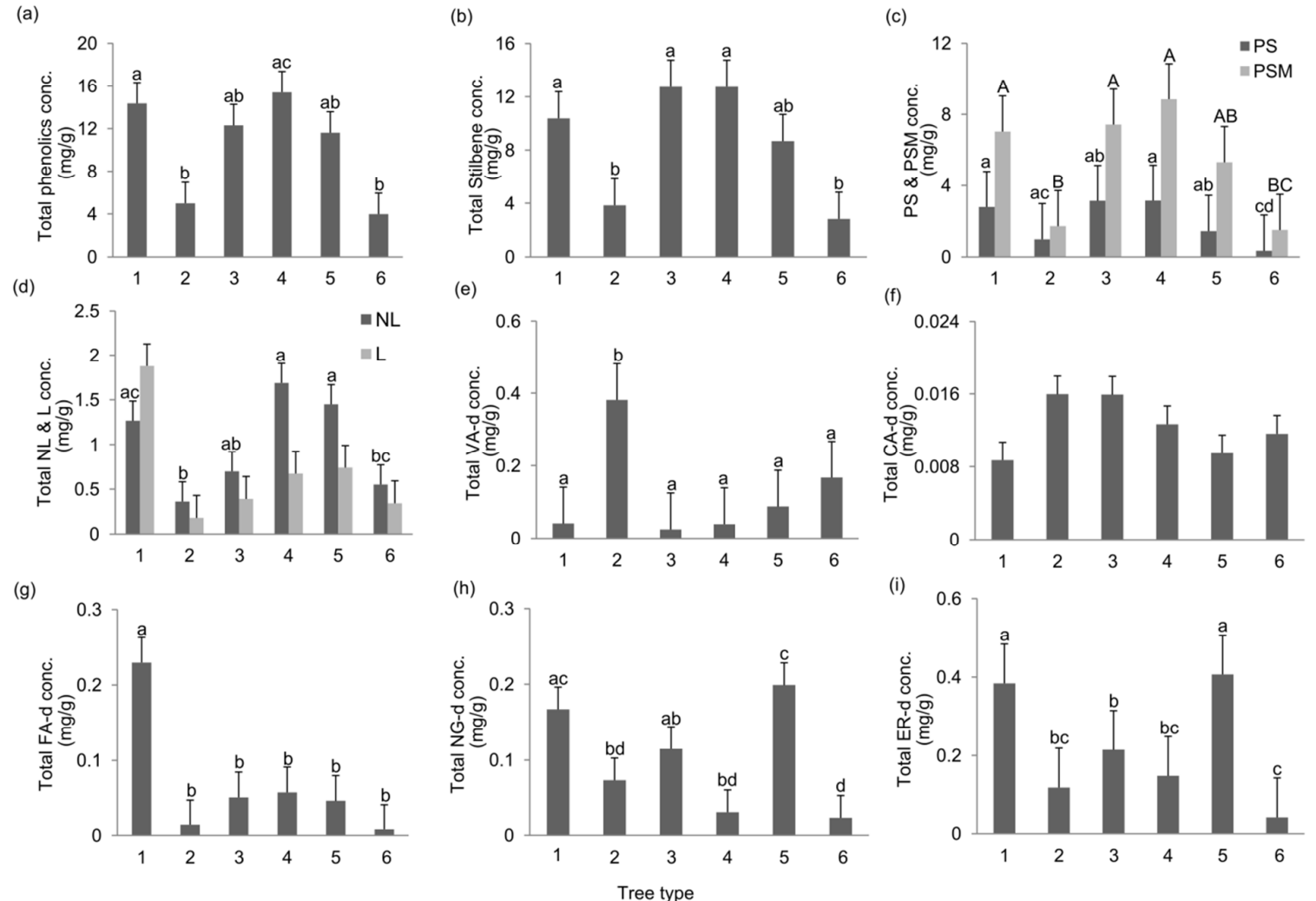

Fig. 2. Phenolic concentrations ( $\mathrm{mg} / \mathrm{g}$, mean $+1 \mathrm{SE})$ in the heartwood from the six Scots pine tree types: 1) living, 2) living with fungi, 3) fallen non-kelo, 4) partial kelo, 5) standing kelo and 6) fallen kelo. Figure includes (a) total phenolics (b) stilbenes (c) pinosylvin and pinosylvin monomethyl ether (d) neolignans and lignans (e) vanillic acid derivatives, (f) cinnamic acid derivative, (g) ferulic acid derivatives, (h) naringenin derivatives and (i) Eriodictyol derivatives. The post-hoc differences using LSD test are indicated by the letters 'a-d'and 'A-C' Within each panel, bars topped by the same/shared letter are not significantly different according to LSD poc-hoc test at $p=0.05$ 

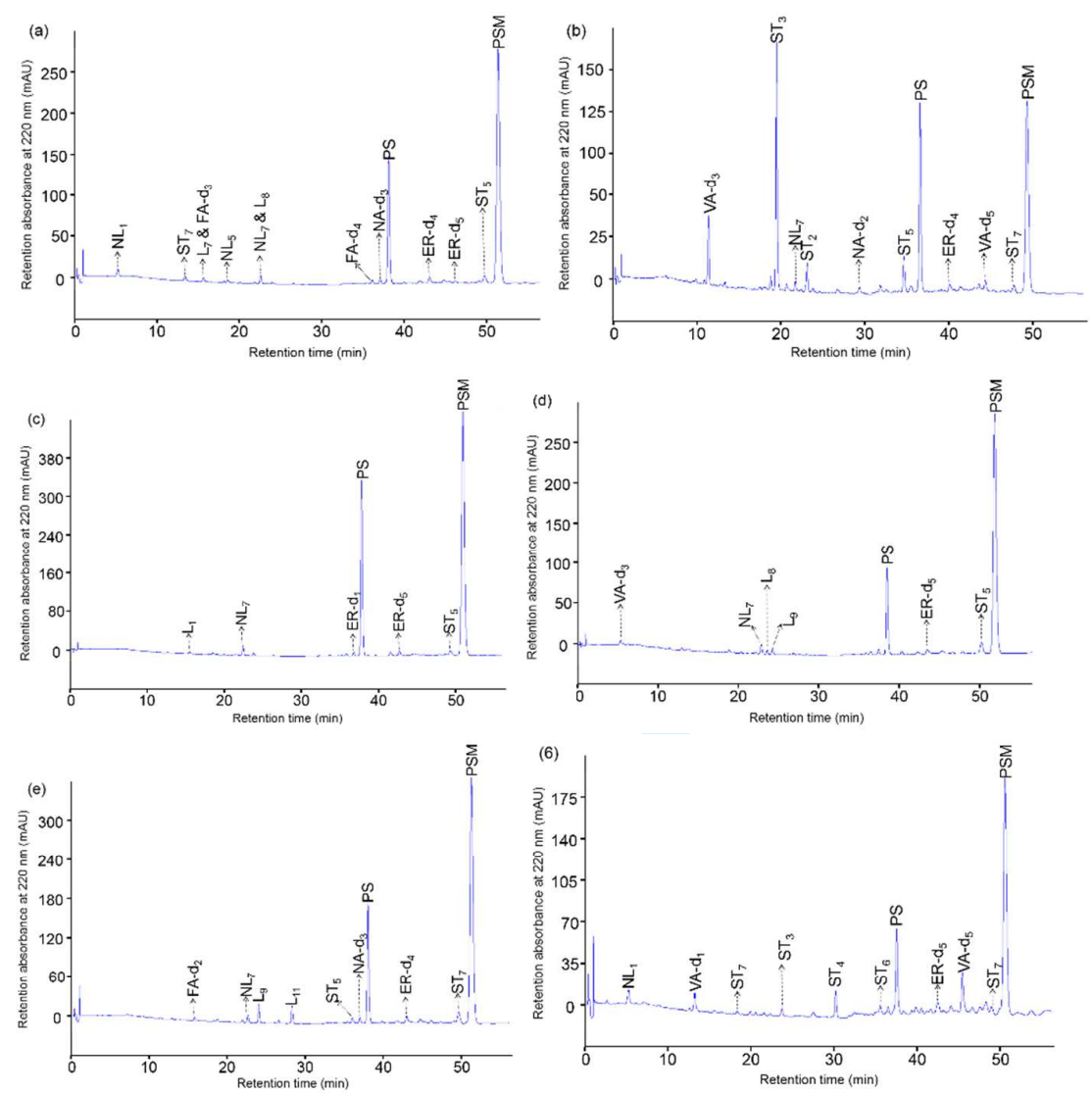

Fig. 3. Spectral chromatograms of one tree sample per each tree type showing the most typical spectral signature characteristics for each tree group (a) living, (b) living with fungi, (c) fallen non-kelo, (d) partial kelo, (e) standing kelo and (f) fallen kelo. 


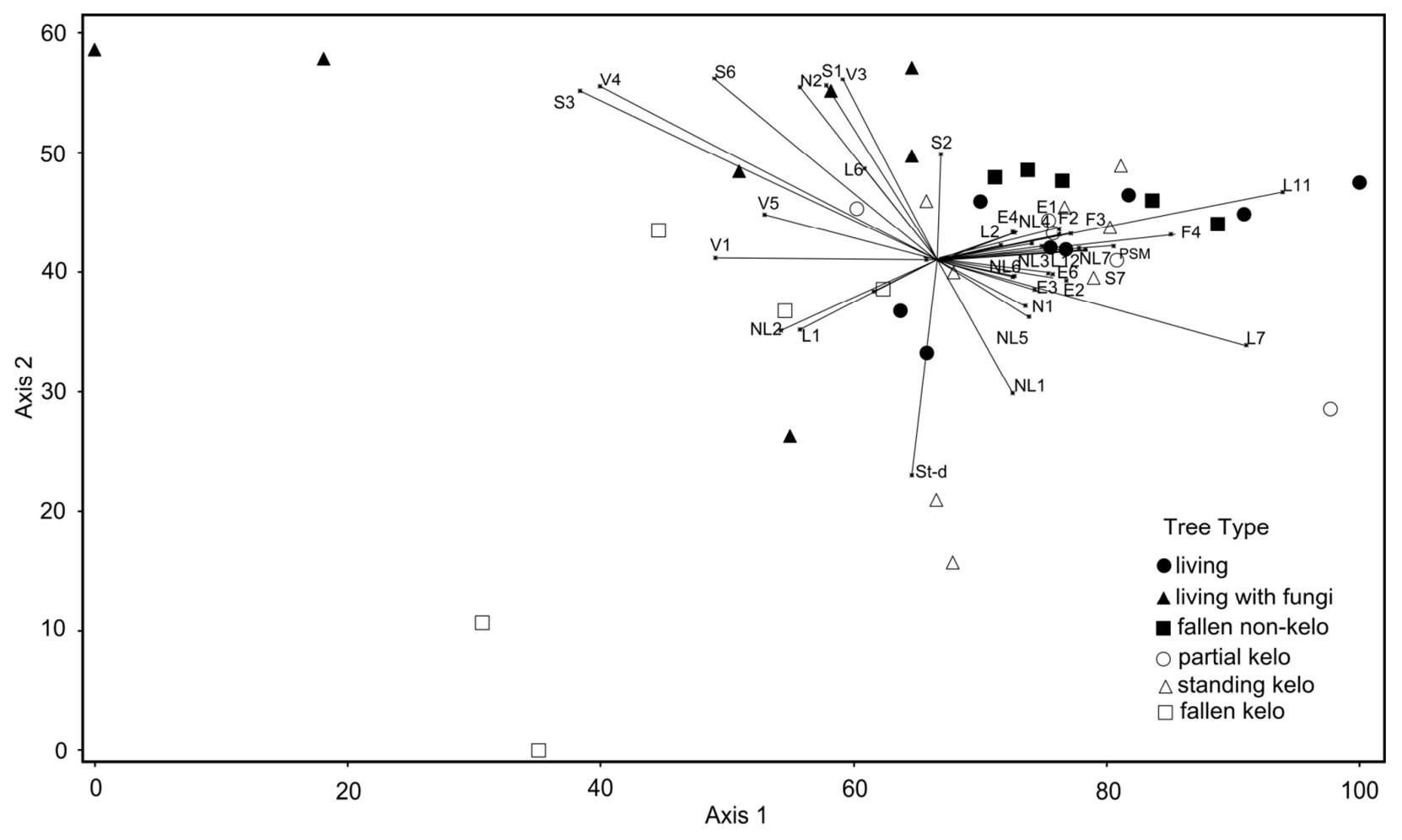

Fig. 4. Non-Metric multi-Dimensional Scaling (NMDS) ordination of the tree types, based on their phenolic composition. The compounds (NL, L, PS, PSM and St-d retaining their abbreviated forms and ' $V$ ' for vanillic acid derivative, 'E' for eriodictyol derivative and 'F' for ferulic acid derivatives; these were found to be significant earlier in the ANOVA analysis) are displayed based on their relative role in the alignment of the different tree type individuals. (The $R^{2}$ value of axis 1 was 0.689 and that of axis 2 was 0.902 ). 

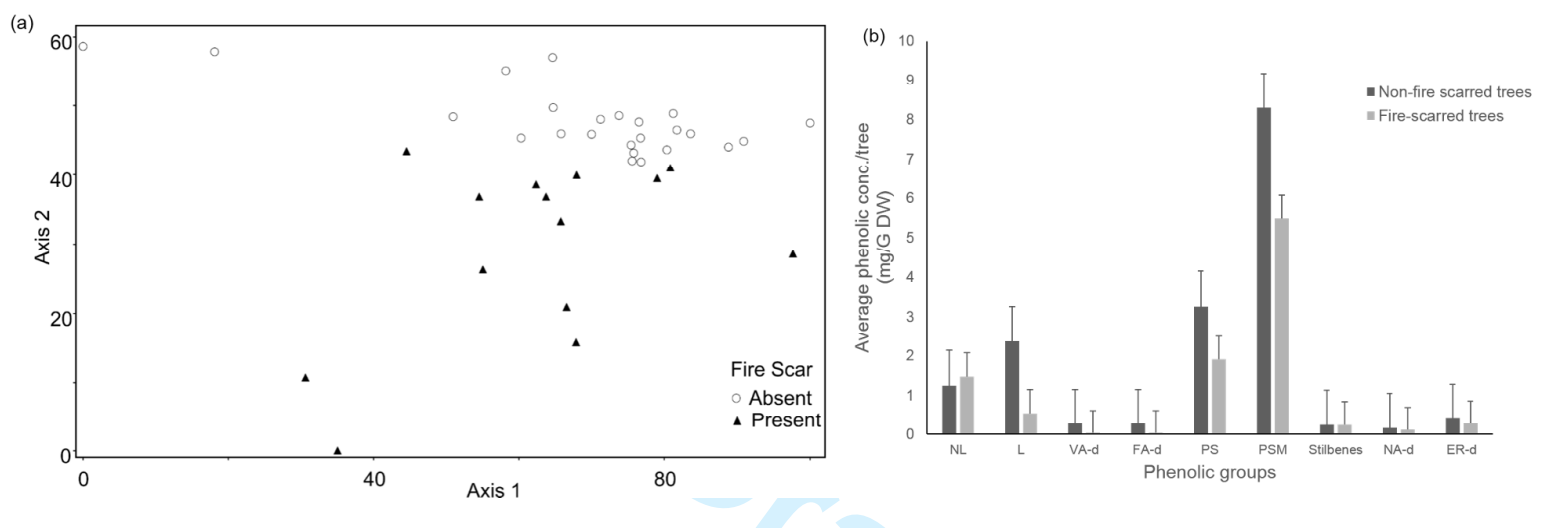

Fig. 5. (a) Non-Metric multi-Dimensional Scaling (NMDS) ordination of the tree samples, separating samples with and without visible fire scars on their trunk. (b) Phenolic concentrations ( $\mathrm{mg} / \mathrm{g}$ DW, mean $+1 \mathrm{SE})$ in the heartwood between trees with and without fire scars. 